\title{
Khoa học Việt Nam với giải thưởng bình duyệt toàn cầu Global Peer Review Awards 2019
}

Hồ Mạnh Toàn (SSHPA) 23/09/2019 11:59

Bất chấp sự khắt khe hơn về quy chuẩn báo cáo phản biện trong năm 2019, các cơ sở đào tạo và nghiên cứu Việt Nam vẫn duy trì được 6 cây bút có mặt trong top $1 \%$ các nhà bình duyệt toàn câu do Global Peer Review Awards vừa công bố.

Ngày 16/9 vừa qua, tuần lễ Peer Review Week 2019 chính thức bắt đầu cùng với nhiều hoạt động, seminar, được tổ chức trên khắp thế giới với chủ đề chính là Quality in Peer Review (Chất lượng trong bình duyệt).

Bình duyệt là hoạt động khoa học ít được chú ý, và các nhà khoa học làm công việc đó với mục tiêu cao đẹp là giúp cho đồng nghiệp khắp thế giới có cơ hội được đánh giá và cải thiện chất lượng tác phẩm. Ngày nay, khoa học nghiêm chỉnh đòi hỏi bình duyệt là bắt buộc, do đó, công tác bình duyệt khoa học giúp giới học thuật có thể xuất bản các nghiên cứu. Mãi tới khi Publons xuất hiện, công tác bình duyệt khoa học mới được thế giới chú ý nhiều hơn. Tuần lễ Peer Review Week thường niên là dịp để cộng đồng học thuật trao đổi khoa học về công tác biên tập hàn lâm, và công bố những dữ liệu có giá trị.

Năm nay, Peer Review Week hướng tới nâng cao nhận thức về các thử thách với bình duyệt học thuật như số lượng ấn phẩm quá lớn, băn khoăn về tính minh bạch, công nghệ chậm cải tiến, hay số lượng các cây bút bình duyệt hạn chế. Hàng loạt các nhà xuất bản lớn và các hiệp hội đồng loạt cổ vũ sự kiện này, và dễ dàng nhận thấy những cái tên quen thuộc như Elsevier, Wiley, Springer Nature, Royal Society, European Association of Science Editors, hay các trang truyền thông khoa học như Scholarly Kitchen. 
Nhắc đến Peer Review Week 2019, chúng ta cũng không thể không nói tới Global Peer Review Awards 2019 (đổi tên từ Publons Peer Review Awards 2018, sau khi chính thức hợp nhất với cơ sở dữ liệu Web of Science và ResearchID của Thomson Reuters trước đây). Đây là sự kiện quan trọng của tuần lễ, nhằm công bố dữ liệu về những người đã âm thầm đóng góp, gác cửa học thuật trên toàn cầu, ở mọi nhà xuất bản suốt cả năm trời.

Global Peer Review Awards sử dụng hệ thống công nghệ thông tin và dữ liệu khổng lồ, gồm hàng triệu bản ghi hồ sơ nhà khoa học, cùng hàng chục triệu báo cáo bình duyệt được Publons ghi nhận, để tổ hợp lại và rút tỉa kết quả, thông báo cho cộng đồng khoa học toàn cầu về mức đóng góp.

Global Peer Review Awards 2019 bao gồm 3 hạng mục chính:

- Các nhà bình duyệt thuộc top $1 \%$ của 22 ngành trong hệ thống Essential Science Indicators (ESI).

- 10 nhà bình duyệt xuất sắc nhất

- 10 nhà biên tập xuất sắc nhất

Dữ liệu thống kê được dựa trên các bản bình duyệt đã xác nhận trong hồ sơ Publons của các nhà bình duyệt tính từ ngày 1/9/2018 đến 31/8/2019. Khác với mục "Assorted" (tổng hợp tất cả các ngành khác nằm ngoài nhóm 22 ngành của ESI) năm ngoái, mục "Cross-field" năm nay thống kê các nhà khoa học đã thực hiện bình duyệt cho các nghiên cứu đa ngành hoặc ở nhiều ngành khác nhau (theo tiêu chuẩn của ESI).

Sự khác biệt lớn nhất trong năm nay so với 3 năm trước đó là quy định chỉ tính các báo cáo bình duyệt cho bản thảo nộp vào các tạp chí thuộc các danh mục Web of Science Core Collection ( $S C I E, S S C I, A H C I$ và ESCI). Điều này giúp đảm bảo chất lượng tốt nhất cho dữ liệu bình duyệt, vốn dựa trên một hệ thống chỉ mục khoa học hàng đầu hiện nay là Web of Science.

Năm nay, có hơn 4.600 chuyên gia tới từ 101 quốc gia và hơn 2.300 trường đại học/các viện, trung tâm nghiên cứu được tôn vinh. Họ đã đóng góp hơn 260.000 báo cáo bình duyệt cho gần 9.000 tạp chí, ước tính tương đương với 1,32 triệu giờ làm việc [1].

\section{Nhìn từ Việt Nam và khu vực Đông Nam Á}


Tìm kiếm cơ sở dữ liệu Publons theo lãnh thổ 'Việt Nam' ở tất cả các ngành cho thấy Top $1 \%$ các nhà bình duyệt từ Việt Nam bao gồm 5 nhà khoa học người Việt và 2 nhà khoa học quốc tế hiện đang công tác tại các trường đại học Việt Nam. Cần lưu ý, đây là dữ liệu chưa đây đủ vì nhiều lý do hay sự phức tạp của thuộc tính dữ liệu: các trường chưa đăng kí với hệ thống, các nhà khoa học Việt Nam đang làm việc tại nước ngoài, hoặc người bình duyệt chưa có tài khoản Publons ResearcherID hợp nhất, v.v.

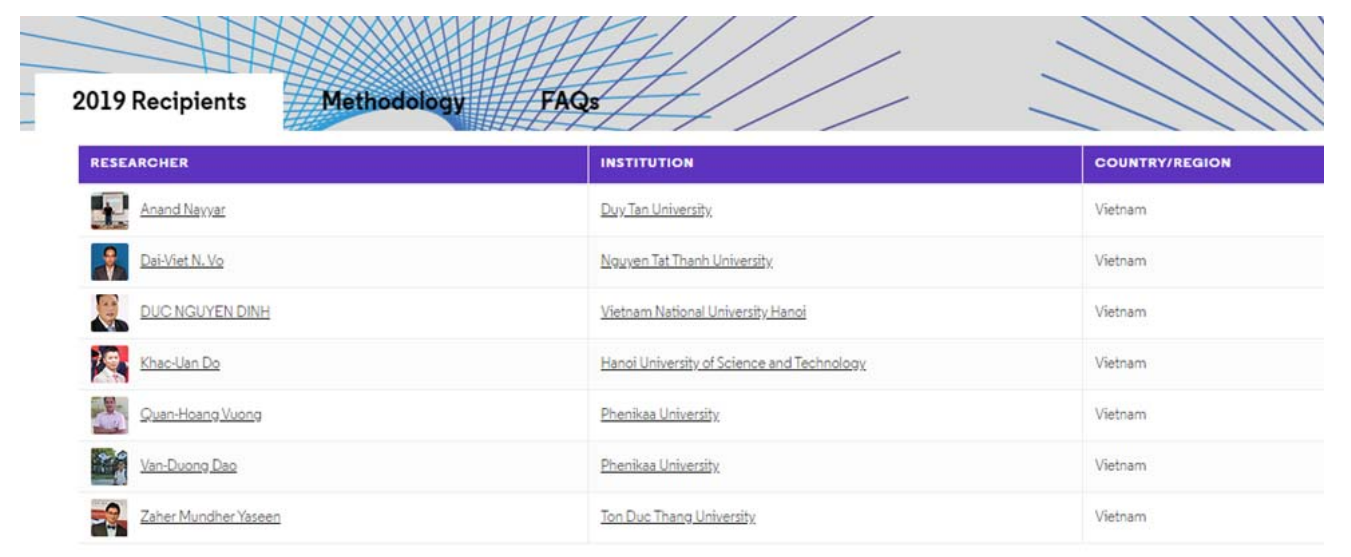

\begin{tabular}{|l|l|l|}
\hline Nhà bình duyệt & Cơ quan công tác & Ngành đạt giải \\
\hline Anand Nayyar & $\begin{array}{l}\text { Trương Đại học Duy } \\
\text { Tân }\end{array}$ & $\begin{array}{l}\text { Engineering; Computer } \\
\text { Science; Cross-field }\end{array}$ \\
\hline Võ Nguyễn Đại Việt & $\begin{array}{l}\text { Trường Đại học Nguyễn } \\
\text { Tất Thành }\end{array}$ & Cross-field \\
\hline Nguyễn Đình Đức & $\begin{array}{l}\text { Đại học Quốc gia Hà } \\
\text { Nội }\end{array}$ & $\begin{array}{l}\text { Material } \\
\text { Engineering; Science; } \\
\text { field }\end{array}$ \\
\hline Đỗ Khắc Uẩn & $\begin{array}{l}\text { Trường Đại học Bách } \\
\text { Khoa Hà Nội }\end{array}$ & $\begin{array}{l}\text { Environment and } \\
\text { Ecology; Engineering; } \\
\text { Cross-field }\end{array}$ \\
\hline Vương Quân Hoàng & $\begin{array}{l}\text { Trường Đại học } \\
\text { Phenikaa }\end{array}$ & Cross-field \\
\hline Đào Văn Dương & $\begin{array}{l}\text { Trường Đại học } \\
\text { Phenikaa }\end{array}$ & Cross-field \\
\hline Zaher Mundher Yaseen & $\begin{array}{l}\text { Trường Đại học Tôn } \\
\text { Đức Thắng }\end{array}$ & $\begin{array}{l}\text { Environment } \\
\text { Ecology; Engineering; } \\
\text { Cross-field }\end{array}$ \\
\hline
\end{tabular}

Các nhà bình duyệt từ các cơ quan Việt Nam trong danh sách Global Peer Review Awards 2019

Ngoài 2 nhà nghiên cứu Đỗ Khắc Uẩn (Trường Đại học Bách Khoa Hà Nội) và Vương Quân Hoàng (Trường Đại học Phenikaa) đều đã có mặt trong Publons Peer Review Awards 2018, thì nhà nghiên cứu Võ Nguyễn Đại Việt cũng từng được ghi nhận năm 2017, nhưng cho Universiti Malaysia Pahang, Kuantan, Malaysia. Nhà nghiên cứu kỳ cựu Nguyễn Đình Đức (Đại học Quốc gia Hà Nội), lần đầu góp mặt trong danh sách. 
Năm 2018, Việt Nam có 6 nhà bình duyệt được ghi nhận, với 1 nhà nghiên cứu quốc tế. Bất chấp sự khắt khe hơn về quy chuẩn báo cáo phản biện trong năm 2019, nền khoa học và các cơ sở đào tạo và nghiên cứu Việt Nam vẫn duy trì được số cây bút có mặt trong Global Peer Review Awards 2019.

So với các nền khoa học khác trong khu vực trong năm 2019, Thái Lan có 13 nhà bình duyệt (2 quốc tế) được ghi nhận, trong khi Indonesia có 5 nhà bình duyệt. Trong khi đó, Malaysia và Singapore vẫn là hai quốc gia với nền khoa học phát triển tốt nhất Đông Nam Á. Chỉ tính riêng trong mục 'Cross-field', Singapore có 16 nhà bình duyệt, còn con số của Malaysia lên đến 54 .

Lân đầu tiên được ghi nhận bởi Global Peer Review Awards 2019, nhà nghiên cứu Đào Văn Dương (trường Đại học Phenikaa, Hà Nội) cho biết: "Tôi khá bất ngờ khi biết mình được có tên trong top $1 \%$ ở Global Peer Review Awards năm nay. Sự kiện này có ý nghĩa đối với các nhà khoa học, là sự ghi nhận những đóng góp trong việc hỗ trợ các nhà biên tập đánh giá các công trình nghiên cứu. Với cá nhân tôi, mỗi lần tham gia phản biện, viết bình duyệt, tôi lại học được từ đồng nghiệp rất nhiều điều từ cách viết bài báo khoa học, các đặt vấn đề, giải quyết vấn đề cũng như cách trả lời ý kiến của phản biện".

Theo báo cáo Global State of Peer Review Report của Publons đưa ra vào năm ngoái, mặc dù công tác bình duyệt có trách nhiệm cao cả là kiểm định chất lượng học thuật, có tới 39\% các nhà bình duyệt chưa bao giờ được đào tạo chuyên sâu. Trong khi đó, số lượng các cây bút phản biện cũng đang bị thiếu hụt nghiêm trọng. Vì thế, tuần lễ Peer Review Week và sự kiện Global Peer Review Awards có vai trò quan trọng trong nâng cao nhận thức và hiểu biết về công việc thầm lặng này.

\section{*Tham khảo:}

[1] Publons. (15-09-2019). Honoring the Top Peer Reviewers for 2019. Publons Blog. Truy cập ngày 17-09-2019 tại đường dẫn: https://publons.com/blog/honoring-the-toppeer-reviewers-for-2019/. 